\title{
STRATEGIC AND FINANCIAL FRAME OF INTERVENTION- CENTERS OF EXCELLENCE AND CENTERS OF COMPETENCE
}

\author{
Venelin Terziev ${ }^{1}$ and Margarita Bogdanova ${ }^{2}$ \\ ${ }^{1}$ Academician of the Russian Academy of Natural History, Moscow, Russia, Prof. D.Sc. (Ec.), \\ D.Sc. (National Security), D.Sc. (Social Activities), Ph.D., National Military University, Veliko \\ Tarnovo, Bulgaria; University of Rousse, Rousse, Bulgaria, terziev@skmat.com \\ ${ }^{2}$ Prof. Ph.D., D.A. Tsenov Academy of Economics, Svishtov, Bulgaria, \\ mbogdanova@uni-svishtov.bg
}

\begin{abstract}
The report presents a comparative analysis of different policies and approaches for management of centers of excellence (CoE) and centers of competence $(\mathrm{CoC})$ in the context of the convergence of science and technology policy. The potential challenges to its successful implementation in Bulgaria are outlined. Best practices and management models in the USA, UK, Denmark and Finland are discussed. Among the main problems in Bulgaria are the short horizon of integration between the efforts of universities and research organizations on the one hand, and business and public sector on the other, the lack of private investments for the development of research, the need for reforms in higher education aimed at improving the quality of education.
\end{abstract}

Keywords: Centers of excellence (CoE), Centers of competence (CoC), convergence of scientific and technological policy.

\section{INTRODUCTION}

In the resent years, the subject of convergence in the scientific and the technological policy grows more and more topical and significant for the development of an economy and even society, based on knowledge. Universities' and research organizations' efforts integration on one hand, and of the businesses and the public sector's on the other hand, becomes a key circumstance for building capacity for innovations. According to some estimation, this is the third economic revolution in human history, which is expected to radically change the way of making business, the environment for living's qualities and the society as a whole.

In this complicated, dynamic environment, higher schools and the research organizations acquire bigger and bigger role of a motor and initiator of development. They are part of the "triple helix" that embraces the system „university - business - government”. They perform the so called „third mission”, directed towards encouraging the relations with users of knowledge and towards facilitating the technologies transfer. This new higher schools social role puts them in front of series of challenges that could be over taken through innovative approaches and use of all possible tools for facilitating the knowledge and technologies transfer.

The Centers of Excellence and the Centers of Competence, which are to be established in Bulgaria in the 
following years, are among the most modern possibilities for intervention up to now.

The present report aims to present a comparative analysis of various policies and approaches for Centers of Excellence and of Competence management in the context of scientific and technological policy convergence, and to outline potential problems and challenges in front of its successful realization in Bulgaria.

The topic about the Centers of Excellence ( $\mathrm{CoE}$ ) and Centers of Competence $(\mathrm{CoC})$ is perhaps the most update and significant for the higher schools at home to the very present moment. It is in the agenda of Operative Programme "Science and Education for Smart Growth“ (OP SESG) and of many higher schools that elaborate project documentation and prepare for managing multi-disciplinary research centers with high potential for scientific results in priority for the country subject fields.

That is why the scientific community's excitement and the expectations of all interested parties for the results and impact of this type of initiatives are great. Beside the planned direct results such as number of publications and hired researchers, in a longer term plan it is expected for the whole picture of scientific infrastructure to change, conditions for successful career for young researcher to be established and the significance of higher schools and research institutions for the development of economy based on knowledge to change.

\section{CENTERS OF EXCELLENCE AND CENTERS OF COMPETENCE - STRATEGIC AND FINANCIAL FRAME OF INTERVENTION}

The Centers of Excellence and the Centers of Competence in Bulgaria are financed under Investment Priority: № 1a. Strengthening the infrastructure necessary for scientific-research and innovation activity, improvement of the capacity for realization of achievements in the field of scientific-research and innovation activity and encouraging the competence centers, and especially the centers that are of interest for Europe, Specific goal 1: „Development of advanced research and market-oriented scientific research“ of Operative Programme "Science and Education for Smart Growth" 2014-2020.

The main goal of intervention is supporting the enhancement of level and of the market orientation of scientific-research activities of the leading scientific organizations in Bulgaria as well as improving the capacity for realizing advanced achievements in the field of scientific research (for CoE), respectively opening opportunities for new partnerships with the business and for establishing new enterprises (for CoC).

The rendered granting is for supporting the building, development and/or modernization of centers of excellence and of centers of competence, regarding overcoming the lack of competitive and internationally recognized scientific-research complexes, and for ensuring high level of scientific research in the fields of interest for the Bulgarian economy, formulated in the Innovation Strategy for Smart Specialization (ISSS).

A minimum of four $\mathrm{CoE}$ and eight $\mathrm{CoC}$ in all four components, corresponding to the ISSS subject fields are expected to be built and start effectively functioning as result of the intervention until 2023. The components and the maximum amount of financing are pointed in Table 1, and the indicators for product, results and impact are presented in Table 2.

Table 1.Components and maximum amount of financing, million of leva

\begin{tabular}{|l|c|c|}
\hline \multirow{2}{*}{ Components/subject fields of ISSS } & \multicolumn{2}{|c|}{ Maximum budget, millions of leva } \\
\cline { 2 - 3 } & CoE & CoC \\
\hline Mechatronics and clean technologies & 70 & 24 \\
\hline Informatics and information and communication technologies & 30 & 13,5 \\
\hline Industry for healthy life and biotechnologies & 70 & 24 \\
\hline New technologies in creative and recreation industries & 30 & 13,5 \\
\hline Totally: & 200 & 150 \\
\hline
\end{tabular}


IJASOS- International E-Journal of Advances in Social Sciences, Vol. V, Issue 13, April 2019

Table 2.Indicators for product, results and impact of CoE and CoC

\begin{tabular}{|c|c|}
\hline Centers of Excellence & Centers of Competence \\
\hline \multicolumn{2}{|c|}{ Indicators for performance (product): } \\
\hline $\begin{array}{l}\text { - } 70 \text { new researchers in the supported subjects } \\
\text { (CoE); } \\
\text { infrastructural objects for scientific researches; } \\
\text { - } 4 \text { newly built infrastructural complexes in CoE; } \\
\text { - } 40 \text { joint scientific-research projects developed } \\
\text { between the CoE and the business. }\end{array}$ & $\begin{array}{l}\text { - } 180 \text { new researchers in the supported } \\
\text { subjects (CoC); } \\
\text { i } 250 \text { researchers, working in improved } \\
\text { infrastructural objects for scientific researches; } \\
\text { - } 8 \text { newly built infrastructural complexes in CoC; } \\
\text { - } 110 \text { joint scientific-research projects } \\
\text { developed between the CoC and the business. }\end{array}$ \\
\hline \multicolumn{2}{|l|}{ Indicators for result: } \\
\hline $\begin{array}{l}\text { Share of the scientific publications among the } \\
\text { first } 10 \% \text { of the most quoted in the ISSS priority } \\
\text { fields - } 4 \% \text {; } \\
\text { - Public expenses to the amount of } 0,03 \% \text { of } \\
\text { the GDP for scientific-research and development } \\
\text { activity (GOVERD plus HERD), financed by the } \\
\text { enterprises. }\end{array}$ & $\begin{array}{l}\text { Public expenses to the amount of } 0,03 \% \text { of the } \\
\text { GDP for scientific-research and development } \\
\text { activity (GOVERD plus HERD), financed by the } \\
\text { enterprises. }\end{array}$ \\
\hline \multicolumn{2}{|l|}{ Additional indicators } \\
\hline \multicolumn{2}{|c|}{$\begin{array}{l}\text { - Number of young scientists under } 34 \text { years, who participate in the scientific-research and } \\
\text { development activities; } \\
\text { - Number of leading national and foreign researchers; } \\
\text { - Number of Ph.D. candidates, post-Ph.D. candidates and graduates in the ISSS subject fields; } \\
\text { - Number of attracted scientists from other countries and/or Bulgarian scientists, who have been } \\
\text { working in foreign scientific organizations; } \\
\text { - Number of trained scientists through trans-national mobility and international cooperation; } \\
\text { - Developed and acquired rights on intellectual property. }\end{array}$} \\
\hline \multicolumn{2}{|l|}{ Target groups } \\
\hline \multicolumn{2}{|c|}{$\begin{array}{l}\text { researchers; entrepreneurs; innovators; teachers; Ph.D. candidates; post-Ph.D. candidates; young } \\
\text { scientists; graduates; participants in scientific researches; university students; school students }\end{array}$} \\
\hline \multicolumn{2}{|l|}{ Expected impact } \\
\hline \multicolumn{2}{|l|}{$\begin{array}{l}\text { Benefits for the entrepreneurship: } \\
\text { - Establishment of spin-off and starting enterprises; } \\
\text { - Development of new/improved products and proces } \\
\text { - Ttransfer of knowledge. } \\
\text { Benefits for the other target groups and for the public: } \\
\text { - Generating of new researches; } \\
\text { - Formation of human capital; } \\
\text { - Development of social capital. }\end{array}$} \\
\hline
\end{tabular}


The centers of excellence and the centers of competence are the largest-scale intervention for Bulgaria in the field of science in the recent years. They are developed as an effort to overtake problems such as low share of investment in scientific-research and development activity (SRDA) and innovation development, insufficient scientific researches' market orientation, underdeveloped infrastructure and equipment.

$\mathrm{CoE}$ and $\mathrm{CoC}$ are large financing schemes with quite a regulative character. They aim at trying to accelerate processes, developed for years in other countries, and at catching up with lagging in public funds financing of expenses for science. But, because of the lack of enough funds for the normal progress development, financing is realized in only few key fields selected after a long status quo as of a certain moment.

Like the rest of the regulative tools, $\mathrm{CoE}$ and $\mathrm{CoC}$ are a form of intervention, at which planning and realization, all inherent risks of such intervention connected with subjective character of management decisions regarding the priority fields of development, evaluation of project suggestions and not at last, regarding the inadequate distribution of public funds for ineffective of unsustainable research centers may occur.

\section{The experience of other countries}

The establishment of $\mathrm{CoE}$ and $\mathrm{CoC}$ in Bulgaria is in execution of the measures of convergence of scientific and technological policy, which is carried out in many other countries, mainly in Organization for Economic Co-operation and Development (OECD). Often, for the purpose, imitation of the achieved by other countries and organizations is applied through transfer of encoded and non-encoded knowledge and experience in the elaboration of policies, organizational forms, procedures and measures. Because of that, the present report presents good practices and models of behaviour that could be modified regarding their adaptation to the particular conditions in Bulgaria.

\section{USA}

In their most popular sense, the Centers of Excellence in the USA are a popular mechanism and model for organization of various types of activities in many organizations in the business sector. In the USA there are many centers of that type existing, in a great part of which universities do not participate directly. CoE in the business organizations are oriented rather towards effective and efficient management of the processes in the relevant organization, i.e. they are connected with the corporate management, including through project management, quality improvement, business analysis, management of processes, etc. The stress is on the training and the skills certification, the knowledge management, the development of standards and methodologies.

In a certain sense, CoE are rather a business model for the companies' activities management, where the stress is directed towards activity optimization and clear focusing on achieving the business goals.

Hewlett Packard's model for center of excellent for example, is directed towards goals like: expenses reduction, efficiency improvement, risk reduction, introduction of good practices, IT structure synchronizing with the company's organizational structure and the business goals with the strategic priorities. The CoE, according to the model's authors, is practically possible to be introduced in any companies, despite their size. It gives possibility for attraction and professional progress of talented experts and not last - introduces standards, which guarantees company's products' and services' quality, despite they are produced by inside subdivisions or outside (outsourcing) suppliers of components or services.

CoE's models in organizational aspect could be various - with a lot or less available resources, with staff employed full-time or part-time, which perform other assignments at the same time - beside the ones in the CoE. Even several CoE can be established at the same organization, directed towards improving the work in different directions.

Anyway, despite the differences, the following common features of CoE could be drawn up:

Good practices and work standards are defined;

To what extent the profile of maturity of the organization/company corresponds to these good practices and standards is evaluated;

Direct (i.e. personal) and/or indirect (i.e. institutional - through tools, samples of documents and others) management and cooperation is ensured at evaluating to what extent the organization has achieved progress in the process of applying the good practices and standards.

These principal formulations precondition CoE's philosophy. Practically they are a system and consistent approach for improving the quality of work of the relevant organization. 
The centers of excellence and of competence in the universities in the USA develop in. In the university of South California, CoE is an inside initiative of the university and aims ensuring popularity and quotability of scientific researches. Joint committee with the participation of academic teachers and representatives of the administration is established. Experts in the center act as leaders, advisers, mentors and support establishing culture of excellence in scientific researches. The center's main activities are carrying out research exhibitions, trainings and workshop meetings.

In essence, University of South California's CoE is rather connected with the system of scientists' career development and its goal is ensuring conditions for the ones, who are highly motivated to carry out their researches. That is why the main stresses in CoE are two: 1) sources of financing, but for individual research projects and 2) mentorship for young scientists, who elaborate doctoral or post-doctoral researches. But also, serious attention is paid to the communication with the media regarding achieving good reputation and ease at financing future projects.

\section{EUROPE}

The variety of research centers of excellence and competence in Europe is great. In some countries, they function for several decades, in others they are newly established and are just starting.

The CoE practice shows that they have three different groups of goals: 1 ) purely scientific (rather connected with fundamental researches); 2) applied researches and innovations; 3) social goals.

CoE's scientific goals are usually directed towards achieving center's international recognition and attractiveness, resources concentration, recruiting leading researchers, creating a critical number of scientists, restructuring the management and organization of the university's scientific researches system, establishing adequate environment for scientific researches, etc.

The picture with the centers of competence is even more variegated. As a rule, they are a mix of training and research goals and measures, where the balance between them varies a lot.

There are exclusions, too. Some CoEs aim achieving excellence in training, like the one in the University of Brighton.

Differences are observed in the ways of project selection, sources of financing of $\mathrm{CoE}$ and $\mathrm{CoC}$, etc. In countries like Sweden, the so called private sources of funds dominate, similarly to the American model. In other countries, mixed financing is applied through combination of budget and public funds. In Denmark and Finland the national funds are accumulated mainly from the privatization of the state companies in the 90s.

In most CoE and CoC the financing through public funds is carried out for a period of 6 to 10 years, which allows elaboration of medium-term plans and programmes and even conduction of risk projects as far as there is enough time for getting control and reaction to the risks before the programme financing is suspended because of bad current results.

All centers are subject to intermediate and final evaluation after preliminary set criteria.

\section{GREAT BRITAIN}

In Great Britain, the decision for financing is taken by seven research councils, established in the 60s. Each council allocates funds in a certain scientific field on the grounds of strategic priorities and annual plans for their realization. The councils give information about sources of financing, publications with free access, scholarships for Ph.D. candidates, rewards of scientists, published results from researches, possibility for participation in public events, policies and standards in the separate directions of financing, etc.

The Economic and Social Research Council for example, functions since 1965, where the economic studies were excluded at first. Beside support at project financing of research programmes, it elaborates also direction for training for Academic Degree Doctor and supports the establishment and financing of 21 centers for training for Academic Degree Doctor, including through giving scholarships.

\section{DENMARK}

Similar to the Bulgarian model is applied in Denmark for centers of excellence and centers of competence since 1993. National programme for CoE financing that gives grants for all scientific fields is constituted.

Totally $100 \mathrm{CoE}$ are financed under a national programme for the entire period of existence (from 1993 to 2016), out of which 37 are functioning to this moment. The rest have been closed after their research programmes had finished.

The CoEs have term of functioning of 10 years. Only top researchers with ambitious ideas are financed. The 
applying procedure is at two stages, where only a short letter for intention - up to 5 pages is submitted during the first stage. Only some of the applicants are asked to elaborate detailed project suggestion at the second stage, which is evaluated by international experts. Before the final decision, the financing programme's board meets each applicant's representatives.

Average $6 \%$ are financed out of all submitted project suggestions. About $13-20 \%$ is invited to elaborate complete project suggestion, $30-30 \%$ of which are approved. The evaluation is completely transparent. The composition of the teams and the evaluators is known and even the applying team has the possibility to review the evaluation yet before the final programme's board's decision.

Each applicant may point three experts, one of whom is selected to participate in the project suggestion's evaluation. The rest two are selected by the evaluating commission on the ground of recommendations by internal and external experts. Each expert evaluates only one project suggestion.

During the interview before the programme's board's final decision, the team leader presents the research idea and the strategy for its realization. The final decision is based on the complete project suggestion; the three ratings (reviews) for each project suggestion; the applicant's answers to the reviewers' questions; the interview with the applicant's leader.

After the final programme board's final decision, the Foundation (donor of the funds) and the center's manager hold negotiations with the institution, where the center would be situated. The negotiations' subject is the co-financing on the behalf of the higher school, the conditions for rendering an office and laboratory space and plans for center's continuing working after the end of financing.

The center's team draws yearly, intermediate and final evaluation. The intermediate evaluation is made after the fifth year on the grounds of center's self-evaluation report, after which the team applies for the second period of financing. The evaluation is reviewed by international experts, who can visit the center and watch its work on site. The final evaluation is made after the $9^{\text {th }}$ year.

\section{FINLAND}

The processes of developing CoE in Finland start in the second half of the 90s, and the country follows the experience of other Scandinavian countries - mainly Sweden and Denmark. But the overall policy of convergence between science and technologies, i.e. between research organizations and universities on one side, and business on the other, starts yet in the 60s and passes through several stages.

During the first stage $\left(60 \mathrm{~s}-80 \mathrm{~s}\right.$ of the $20^{\text {th }}$ century), the basic structures in several directions form:

Elaboration of programmes and new planning mechanisms, first of which is a Finnish plan for improving the financing of scientific-research and development (SRDA);

Establishment of a political council at a high level for formulating directions in the scientific-technological policy and for coordination of the science and technologies development activities among the various ministries (the coordination model is borrowed from Sweden, which borrowed it from the USA);

Administration reorganization, when new mechanisms for planning, coordination and financing of university research are established; part of the reform is the establishment of a fund for new research grants;

Introduction of measures for improvement of the conditions for the industrial scientific-research and development activity, establishment of a new fund for encouraging company researches;

Development of higher education as resource for feeding the research centers with qualified scientists.

The second stage is connected with enhancing the technological orientation (80-90s of the $20^{\text {th }}$ century). Schemes are elaborated and organizations are established for technological transfer, diffusion and commercialization, i.e. the need of the so called mediators in the transfer of knowledge and technologies, who are a key element in the national innovative system, emerges. National web of technological parks and centers is established, where spin-off projects and incubators are developed. The possibilities for financing innovative projects with public and private funds at national as well as at regional level grow.

The third stage starts in the 90s and the efforts are already directed towards establishing society based on knowledge. Visible results under the goals set yet during the first and second stage of transformation of the Finnish system of higher education and scientific research are achieved - well functioning system of universities and governmental research institutes, new and renovated mechanisms for planning and financing SRDA with public and private funds, good results with the industrial innovations. Finland lines up among the world leaders in innovations and technologies development. The society of knowledge concept is realized through and is supplemented by better and better structured national innovative system (NIS), 
where all subjects and players on the science and technologies market participate. The country stakes on growth based on knowledge, and for that, measures in several directions are undertaken: SRDA, education, conditions for competition, laws and regulations for the intellectual property, national and international webs for cooperation and technological transfer.

The policy for growth based on knowledge turns being winning. In the $90 \mathrm{~s}$, when the country enters recession, namely the measures connected with science and technologies development contribute to the fast going out of the crisis. Since 1995, when the country becomes a full member of the EU, Finland participates actively in all EU framework programmes, and particularly the funds for support of science and technologies in the remote regions of the country increase.

Currently, the functioning centers of excellence form network with clearly set goals, managed jointly by the Finnish Academy, the universities and the research institutions that participate in the centers.

One of the important factors for Finland's success is the complete political support on the behalf of the government, which elaborates and implements a plan for training and research that includes measures for ensuring resources and for keeping talents necessary for establishing and strengthening the centers of excellence. The SRDA budget is also increased - from 2,5 to 2,9 \% of the GDP. Part of the measures is connected with the establishment of a national innovative system, where the expenses for its starting are covered by the state companies' privatization.

This way the measures for the implementing the scientific research stimulating policy in Finland are integrated. Political, economical and cultural conditions that favour the development of not only centers of excellence and competence but also of society based on knowledge are established.

\section{Applicability of the good practices - some conclusions about Bulgaria}

The review of the practices and approaches for $\mathrm{CoE}$ and $\mathrm{CoC}$ management in the different countries gives grounds for drawing some conclusions and more general commentaries about their applicability for Bulgaria.

\section{Number of subject fields, admissible for intervention under the schemes for CoE and CoC}

An important feature for the Bulgarian model is the extremely concentrated character of subject fields, formulated in the Innovation Strategy for Smart Specialization (ISSS) - totally four for the country, in which $\mathrm{CoE}$ and Coc would be developed. The review of the rest of the member states' priority fields shows that they are average about 8 , and in countries like Portugal they reach 17. Even small economies like the ones of Latvia and Estonia are with 5, respectively 6 fields of priority stimulation.

The four subject fields for Bulgaria, beside that they are priority within ISSS, they are also leading in the project of the National Strategy for development of scientific research to 2025, as far as both documents are to be integrated on contents. Without commenting the methodology of selecting admissible fields of intervention, we would be able to make the conclusion about the quite narrow character of specialization in Bulgaria, and the missed benefits for other fields of science and other sectors of economy, which stay constantly aside from the government's attention and would progress far slower in the coming years.

\section{Average amount of annual financing}

The preliminary analysis shows that the expenses for $\mathrm{CoE}$ and $\mathrm{CoC}$ in Bulgaria are planned with very big reserve as far as the average amount of annual financing with public funds for $\mathrm{CoE}$ and $\mathrm{CoC}$ in our country exceeds significantly the one of the centers in the developed countries (Table 3).

Table 3. Average annual budget for financing $\mathrm{CoE}$ and $\mathrm{CoC}$ with public funds in Bulgaria, millions of EUR

\begin{tabular}{|l|c|c|c|c|}
\hline \multirow{2}{*}{ Components/subject fields of ISSS } & \multicolumn{2}{|l|}{$\begin{array}{l}\text { Max. budget of a } \\
\text { single center }\end{array}$} & \multicolumn{2}{l|}{$\begin{array}{l}\text { Annual budget } \\
\text { (6 years) }\end{array}$} \\
\cline { 2 - 5 } & CoE & CoC & CoE & CoC \\
\hline Mechatronics and clean technologies & 35 & 12 & 5,83 & 2 \\
\hline $\begin{array}{l}\text { Informatics and information and communication } \\
\text { technologies }\end{array}$ & 15 & 6,75 & 2,5 & 1,125 \\
\hline
\end{tabular}


IJASOS- International E-Journal of Advances in Social Sciences, Vol. V, Issue 13, April 2019

\begin{tabular}{|l|c|c|c|c|}
\hline Industry for healthy life and biotechnologies & 35 & 12 & 5,83 & 2 \\
\hline $\begin{array}{l}\text { New technologies in creative and recreation } \\
\text { industries }\end{array}$ & 15 & 6,75 & 2,5 & 1,125 \\
\hline Average: & & & 4,17 & 1,56 \\
\hline
\end{tabular}

If in Finland the annual financing with public funds for one center is average 0,5 million, and in Norway it reaches up to 1,4 million Euros, In Bulgaria the public expenses reach average 4,17 million Euros for CoE and 1,56 million Euros for $\mathrm{CoC}$, i.e. the annual budgets of both types of centers exceed the values for Finland and Norway even nominally. When the difference in the purchasing power parity in Bulgaria and in the two other pointed countries is also taken into consideration, then the actual purchasing power of the annual budgets in our country is much higher.

Of course, these calculations are made under the condition that only $4 \mathrm{CoE}$ and $8 \mathrm{CoC}$ are financed, what are the minimum indicators for product under both schemes. If the number of centers increases, the total and the annual budget are reduced and probably would reach the limits of the centers in the Scandinavian countries.

However, this means that the funds for $\mathrm{CoE}$ and $\mathrm{CoC}$ are planned at a very high percentage of reserve and, compared with the low indicators, this rather shows highly pessimistic attitude for their results, and double insuring with quite exaggerated budget compared the ones of other $\mathrm{CoE}$ in European countries.

Anyway, it is to be pointed that many of the centers in Western Europe rely also on funds from private sources that exceed many times the public funds. The total financing varies from 27 million Euros per year in Sweden to 43 million Euros for the Danish CoE.

\section{Uniting of several higher schools into one center}

One of the most important stresses regarding CoE and CoC in our country is the necessity of uniting and participation of several higher schools into one center. The reasons for that are connected with mainly the insufficient scientific capacity of most of the higher schools (measured through science-metric indicators) as well as in the management of scientific researches. Similar type of uniting in the other countries is rather exclusion. Even, not seldom, few centers of excellence are established in the same university, depending on the scientific fields in the higher school (33 centers in the University of Helsinki, 25 - in the University of Copenhagen, 21 centers in the Lund University - Sweden).

Potential uniting of higher schools for participation win joint center is practically a very important step in the Bulgarian higher schools and a first step towards concentration of efforts in favour of excellence results. The traditional relationship between the universities in Bulgaria, mainly as competitors for limited resources and limited number of applicants, is already moving to new stage, when the relationships of cooperation become important enough and partnership is realized on far wider base, than it was up to now. At the same time, scientific researches become more and more important source of funds, which in some cases might even dominate over the expenses for training. This changes the conditions for the strategic and financial management and leads to new requirements towards the management of higher schools and of researching institutions.

A possible effect from that is the change of competencies in the universities themselves. Here not only and not so much the competencies connected with scientific-research projects and the fulfillment of particular tasks in them are considered, but also purely entrepreneur and administrative competencies on the commercialization of scientific researches and the transfer of knowledge and technologies. According to a study of British scientists [6], the time and efforts on such type of activities will increase in the following years for the sake of "the pure” teaching and scientific studies.

The network cooperation, the distributed infrastructure, the joint responsibility for the results are a significant challenge and, at the same time, give opportunity for a high added value, when managed adequately and competently. However, they require culture of cooperation that is only now to be established in Bulgaria.

\section{Dominating nature of the public funds for financing}

Another characteristic feature of the Bulgarian $\mathrm{CoE}$ and $\mathrm{CoC}$ is the dominating nature of the public funds for financing, respectively the absence of rendered by the business private funds. The main reason is that business does not recognize the long-term benefit from participating in $\mathrm{CoE}$ and $\mathrm{CoC}$ and is not ready to invest in them but looks for short-term one. It rather wants to be a net beneficiary of the public support and 
this, within relatively short terms. This is a very important feature, which strongly unbalances the interests in the $\mathrm{CoE}$ and the $\mathrm{CoC}$ and creates serious problems and fear regarding the sustainability of their potential results.

\section{Short convergence horizon of the scientific and technological policy}

While the public consensus for concentrating public and private resources with a view to achieving excellence in the developed countries has gradually and naturally increased, in Bulgaria these processes unfold for far shorter term. All measures have to be implemented within few years - from policies elaboration, through establishing the institutions and the process's organization to the very start of $\mathrm{CoE}$ and $\mathrm{CoC}$. As a result, the attitudes of all interested parties are not so synchronized and unidirectional as they are in Denmark of in Finland, for example.

The reasons for theses short terms, of course, are well known. This is the delay in establishing organizational environment for the development of economy based on knowledge in our country, and at the same time, the political will for the necessary changes to be realized quickly. These short terms, however, bring the risk of the planned convergence of policies and measures to not happen and no integration of the efforts of universities and the business for growth based on knowledge to occur. And if the public sector undertakes the necessary steps for catching up with the missed, business does not realizes to a great extent the significance of the made interventions, which, in the end of the day, are to support namely the industry in the preliminary agreed upon directions.

\section{$\mathrm{CoE}$ and $\mathrm{CoC}$ - rather a financial tool, than strategic approach for change}

One of the important conclusions, which are to be made, is that the CoE and the CoC should not be observed only as source of several millions of leva but as a tool for changing the model of management, the strategy and structure of institutions, where such centers would be established (host institutions).

As it was mentioned earlier, the philosophy of the CoE is connected with defining standards for work, with assessment of to what extent the organization or the team of the center have capacity to apply these standards as well as management and support of achieving excellence at applying the good practices and standards.

The standards for excellent achievements are only hinted in the documents on both financing schemes. They are not even defined as such, but as preliminary conditions in order the team to apply. Availability of centers/offices for technologies transfer in the higher schools, strategy for excellent achievements in scientific researches, policy and rules for intellectual property are included here; policy and rules for exploitation and commercialization of the scientific researches' results, including structure for knowledge and technologies transfer; rules for the European Charter for Researchers and the EC Code of Conduct of Recruitment institutional application, etc. These documents, however, form only part of the standards for work. They are the framework, which is under establishment in most of the higher schools in Bulgaria at the moment and for which successful implementation serious interventions in the management at internal university level are necessary.

This is expected to be one of the difficult challenges in front of the sustainability of the $\mathrm{CoE}$ and $\mathrm{CoC}$ and respectively in front of the higher schools, where the centers are situated (host institutions). These standards and good practices introduction in this case is inspired from outside, and not from the conscious necessity for improving the organization's work in a certain direction - in this case, the university's scientific research. In these cases the necessity of change is not recognized, there is no "owner" of the process, who to effectively and efficiently manage the changes at organizational level, because of which great part of them are left uncompleted, formal, useless. Such kind of changes is rather to the detriment of the organization as far as they consolidate the resistance inside it. The managers at the medium and lower levels are highly skeptic and perceive the changes as useless, boring and unreasonable, required by insane bureaucrats.

The alternative is in elaborating and applying efficient and profound communication strategy and in undertaking actions for explaining the process, for drawing and engaging the researchers and them to become followers of the idea so that they continue developing it and to actively participate in its realization at organizational level.

According to the corporate management's rules, effective change requires for there to be a main body of leaders at sufficiently high level in the organization, who to recognize the necessity for change and to act coordinated as team in the process of improvement.

The striving for excellent achievements is a way of working, not a tool for winning granting. It has and exceptional potential for sustainability, when applied adequately. Otherwise, it brings only short-term, 
unsustainable results. The bad examples in this sense are numerous.

Operative Programme „Science and Education for Smart Growth“ (OP SESG) 2014-2020 has two main tasks:

To be among the key tools for achieving the goals, adopted by the Republic of Bulgaria (RB) within the frame of the Europe 2020 Strategy (achieving 1,5\% of GDP, invested in scientific-research and development activity (SRDA); a share of $36 \%$ of the population aged between 30 and 34 with higher education (HE); reduction of the share of the premature school leavers to $11 \%$; reduction of the number of people living in poverty by 260000 ; and increasing employment to $76 \%$ );

To serve as an efficient tool for applying policies of convergence, in compliance with the agenda at national and community level.

The mentioned tasks define the Europe 2020 Strategy and its leading initiatives: Programme in the field of the digital technologies for Europe; Union for innovations; Youth in movement; Europe for effective use of resources; Industrial policy for the era of globalization; Programme for new skills and working places; European platform against poverty, as starting point of the planning process.

Financial intervention through the operational programme corresponds to the goals of Europe 2020 Strategy offering solutions through the set priority axes (PA) for:

Ensuring access to quality education: condition for adequate participation of civilians in the inclusive economy /PA 2 - quality education, PA 3 - accessible education/.

Building scientific, research and innovation potential in RB: condition for development of intelligent economy /PA 1 - development of scientific-research potential/; PA 2 - HE quality, access to and quality of life-long learning, vocational education and training, all of them are basic activities for overcoming the gap between scientific-research and educational systems on one hand, and the needs of business and labour market on the other hand/. The strong synergy between these additional measures is an argument in favour of using the approach of two funds in this operational programme - financing from the European Regional Development Fund for PA1 and from the European Social Fund for PA2 and PA3.

The financial intervention through OP SESG corresponds to the goals of the National Development Programme: Bulgaria 2020 and provides for solutions for achieving the goals set in strategic priorities 1 . „Education, qualification and employment for inclusive growth“/Measures under PA2, PA3/ and 2. „Scientific researches, innovations and investments for smart growth" /Measures under PA1/(2018a-0; 2012a; Dag Aksnes , 2012b; Etzkowitz, Leydesdorff, 1998a; Etzkowitz, 2000a; Gulbrandsen, Slipersaeter, 2007a; Miller, McAdam, McAdam, 2014a; Lemola, 2002a; 2017a-b; 2010a).

\section{CONCLUSION}

The conclusions about the necessary future actions are drawn on the grounds of the summarized SWOT analysis (Table 4).

Macroeconomic and structural policies are necessary to use the possibilities and to prepare the possibility for meeting the threats or for reducing the consequences if they occur. In this sense, the policies should:

Exploit the strong aspects through focusing on the information and communication technologies (ICT) and on the cultural-historical heritage as well as to give opportunity to the well educated to stay in the country;

- Direct towards overcoming the weaknesses through focusing upon clean energy and resource effectiveness by improving the possibilities of labour force;

- Exploit market's global possibilities through competitiveness support (the expenses for work reduce through innovations but not always do they ensure better quality of life) and attract attractive direct foreign investments;

- Prepare for potentially bigger and global competition through support of competitiveness in fields, where Bulgarian economy is strong. 
Table 4. SWOT analysis of innovation and scientific-research potential.

\begin{tabular}{|c|c|}
\hline Strong aspects & Weak aspects \\
\hline Availability of enterprises with high growth & Limited innovations dynamics, demonstrated by global \\
\hline Accumulated experience and investments in & patentıng and ni \\
\hline mechatronics and the connected economic activities & Ineffective educational system and lack of qualified work \\
\hline High share of university graduates & $\begin{array}{l}\text { graduates) } \\
\text { grate }\end{array}$ \\
\hline $\begin{array}{l}\text { Tradition in fundamental scientific researches, including } \\
\text { biotechnologies }\end{array}$ & $\begin{array}{l}\text { Low share of GERD/GDP (GERD / GDP = Total } \\
\text { expenses for SRDA / GDP) }\end{array}$ \\
\hline $\begin{array}{l}\text { Highly qualified researchers in the field of physics, } \\
\text { chemistry, computer technologies and biotechnologies }\end{array}$ & $\begin{array}{l}\text { Low share of BERD/GDP (BERD / GDP = Business } \\
\text { expenses for SRDA / GDP) }\end{array}$ \\
\hline High rate of growth of culture and creative industries & $\begin{array}{l}\text { Low Small and Medium Enterprises' /SME/ inclination } \\
\text { to join the innovative activities' web }\end{array}$ \\
\hline & $\begin{array}{l}\text { Limited cooperation between business and the } \\
\text { academic community }\end{array}$ \\
\hline & "brain-drain" \\
\hline & Low entrepreneur's and innovations' culture \\
\hline Possibilities & Threats \\
\hline $\begin{array}{l}\text { The strong aspects' development could make the } \\
\text { investment in leading high-technology sectors attractive }\end{array}$ & Highly qualified teachers and researchers' aging \\
\hline $\begin{array}{l}\text { Innovations improvement through use of the EU } \\
\text { competition funds and of the given reserves }\end{array}$ & $\begin{array}{l}\text { Possibilities for qualified researchers to work abroad in } \\
\text { better conditions. The quickly changing environment }\end{array}$ \\
\hline $\begin{array}{l}\text { Wide introduction of innovations and improving young } \\
\text { generation's entrepreneur culture }\end{array}$ & \\
\hline $\begin{array}{l}\text { Active usage of the Bulgarian diaspore scientists - } \\
\text { potential for the brain movement }\end{array}$ & \\
\hline Increasing the research cooperation in world trends & \\
\hline
\end{tabular}

The policies should:

Be based on the strong aspects, hence to invest in mechatronics and the bio-based and the connected sectors and to encourage fundamental researches that could put to work the process of entrepreneur discovery;

Eliminate weaknesses through improving the quality of labour force's education and more particularly, to draw the Bulgarian diaspore through support of researchers to come back temporary or for constant and to share the acquired knowledge, to establish better conditions for entrepreneurship for the younger generation, focusing on some clusters of potential investors' interest;

Soften the effect of the threats through training and hiring new researchers in order to compensate the aging qualified staff and to compete with other countries, their attracting, as well as to use flexibility and to adapt to the changing global competitive pressure.

\section{REFERENCE LIST}

Centers of Excellence (2018a). http://dg.dk/en/centers-of-excellence-2/.

Centers of Excellence in Research (2018b). http://www.aka.fi/en/research-and-science-policy/centres-ofexcellence/.

Center for Excellence in Research (2018c). https://research.usc.edu/about/vp/cer/.

Centres of Excellence in the Nordic countries, (2012a). Nordic Institute for Studies in Innovation, Research 
and Education (NIFU), 4/2012.

Dag Aksnes et all. (2012b). Centres of Excellence in the Nordic countries. Nordic Institute for Studies in Innovation, Research and Education (NIFU), 2012, p.8.

Etzkowitz, H., Leydesdorff, L. (1998a). The endless transition: A triple helix of universityindustry-government relations. Minerva, 36, 203-288, 1998.

Etzkowitz, H. (2000a). Tech transfer, incubators probed at triple helix III. Research Technology Management, 43(6): 4, 2000.

Gulbrandsen, M., Slipersaeter, S. (2007a). The third mission and the entrepreneurial university model. In: Bonaccorsi, A., Daraio, C. Universities and Strategic Knowledge Creation. Specialization and Performance in Europe. Cheltenham: Edward Elgar, 2007, pp. 112-143.

How to Build More Impactful Centers of Excellence, Industry Week, Jun, 17, 2014. (2018d). http://www.industryweek.com/operations/how-build-more-impactful-centers-excellence.

Miller, K., McAdam, M., McAdam, R. (2014a). The changing university business model: a stakeholder perspective, R\&D Management, 44, 3, 2014, p.265-287.

Lemola, T. (2002a). Convergence of national science and technology policies: the case of Finland. Research Policy 31 (2002) pp. 1481-1490 http://blogs.helsinki.fi/changingdynamics/files/2010/09/Lemola_Convergence_of_ST_policies.pdf.

RCUK Executive Directorate delivery plan 2016-2017. (2017a). http://www.rcuk.ac.uk/documents/documents/rcukexecutivedirectoratedeliveryplan-pdf/.

Road map to a Centre of Excellence. (2017b). A business white paper. https://www.hpe.com/h20195/v2/GetPDF.aspx/4AA2-4224EEW.pdf.

The Centre for Excellence in Teaching and Learning through Design CETLD. (2018e). http://arts.brighton.ac.uk/projects/cetld.

Analysis of the state of research in Bulgaria. (2010a), https://www.fni.bg/?q=node/20.

Europe 2020 - flagship initiatives: (2018f). http://ec.europa.eu/europe2020/europe-2020-in-anutshell/flagship-initiatives/index_bg.htm.

Izpalnenie na Plana za deystvie po ISIS. (2018g). (Изпълнение на Плана за действие по ИСИС), https://www.mi.government.bg/bg/themes/inovacionna-strategiya-za-inteligentna-specializaciya-narepublika-balgariya-2014-2020-g-i-proces-na-i-1470-287.html.

Inovatsionna strategiya za inteligentna spetsializatsiya: na Republika Balgariya (2018h). (Иновационна стратегия за интелигентна специализация: на Република България 2014-2020). https://www.mi.government.bg/bg/themes/inovacionna-strategiya-za-inteligentna-specializaciya-narepublika-balgariya-2014-2020-g-i-proces-na-i-1470-287.html.

Natsionalna programa za razvitie: Balgariya 2020. (2018i). (Национална програма за развитие: България 2020), http://www.strategy.bg/StrategicDocuments/View.aspx?ld=765.

Natsionalna patna karta na nauchnata infrastruktura, 2014. (2018j). (Национална пътна карта на научната инфрраструктура, 2014), http://www.strategy.bg/StrategicDocuments/View.aspx?ld=919.

Natsionalna strategiya za razvitie na nauchnite izsledvaniya 2020. (2018k). (Национална стратегия за развитие на научните изследвания 2020), http://www.strategy.bg/StrategicDocuments/View.aspx?lang=bg-BG\&ld=708.

Operativna programa „Nauka i obrazovanie za inteligenten rastezh“ 2014-2020. (2018I). (Оперативна програма „Наука и образование за интелигентен растеж“ 2014-2020), http://sf.mon.bg/?go=page\&pageld=36.

Strategiya „Evropa 2020“ (2018m). (Стратегия „Европа 2020“), http://ec.europa.eu/europe2020/index_bg.htm.

Strategiya za razvitie na vissheto obrazovanie v Republika Balgariya za perioda 2014 - 2020 g. (2018n). (Стратегия за развитие на висшето образование в Република България за периода $2014-2020$ г.), http://www.strategy.bg/StrategicDocuments/View.aspx?ld=962.

Smart Specialisation Platform (20180). http://s3platform.jrc.ec.europa.eu/regions/PT?s3pv=1. 